\title{
DRENAGEM INTERNA E LIXIVIAÇÃO DE NITRATO EM UM LATOSSOLO SOB SUCESSÃO MILHO-BRAQUIÁRIA-MILHO, COM DIFERENTES DOSES DE NITROGÊNIO(1)
}

\author{
Flávia Carvalho Silva Fernandes ${ }^{(2)} \&$ Paulo Leonel Libardi ${ }^{(3)}$
}

\begin{abstract}
RESUMO
A adubação nitrogenada ideal deve ser definida para satisfazer a necessidade da cultura, mas com o mínimo de risco ao ambiente. Para isso, é necessário que a recomendação da adubação nitrogenada seja a mais exata possível. $O$ presente trabalho foi desenvolvido em um solo de textura areno-argilosa, com o objetivo de avaliar a drenagem interna e a lixiviação de $\mathrm{NO}_{3}^{-}$à profundidade de $0,80 \mathrm{~m}$ com o tempo, em uma sucessão de culturas sob plantio direto, utilizando-se sulfato de amônio marcado com o isótopo estável ${ }^{15} \mathrm{~N}$, em diferentes doses. As avaliações foram feitas em dois cultivos de milho safrinha, o primeiro no ano agrícola de 2006 e o segundo em 2007, e em um de braquiária na entressafra. Os tratamentos consistiram de doses de $\mathrm{N}$ de 60,120 e $180 \mathrm{~kg} \mathrm{ha}^{-1}$, na forma de sulfato de amônio marcado $\left({ }^{15} \mathrm{~N}\right)$, e um tratamento testemunha, sem aplicação de $\mathrm{N}$. $\mathrm{O}$ adubo marcado foi aplicado em subparcelas previamente definidas, apenas no primeiro cultivo do milho (safra 2006). A drenagem interna foi obtida a partir da densidade de fluxo de água calculada pela equação de Darcy-Buckingham, na qual a condutividade hidráulica e o gradiente de potencial total foram estimados a partir de leituras diárias de tensiômetros de mercúrio, instalados nas profundidades de 0,70, 0,80 e $0,90 \mathrm{~m}$. A condutividade hidráulica em função do potencial mátrico na profundidade de $0,80 \mathrm{~m}$ foi determinada, no campo, pelo método do perfil instantâneo, usando tensiômetros e curvas de retenção. A densidade de fluxo de água foi também usada, juntamente com a concentração de $\mathrm{NO}_{3}^{-}$e a porcentagem de átomos de ${ }^{15} \mathrm{~N}$ da solução no solo, para estimar a lixiviação do $\mathrm{NO}_{3}^{-}$total e daquele derivado do fertilizante. A solução no solo foi coletada por meio de extratores com cápsula porosa, instalados na profundidade de $0,80 \mathrm{~m}$. A drenagem interna diminuiu com o aumento das doses de $\mathrm{N}$ aplicadas para a sucessão de culturas estudada, variando de 31,5 a 73,4 \% da precipitação pluvial total $(97 \mathrm{~mm})$ durante o primeiro cultivo de milho, de 26,1 a $58,1 \%$ da precipitação pluvial total $(695 \mathrm{~mm})$ no cultivo da
\end{abstract}

\footnotetext{
(1) Trabalho apoiado pela FAPESP. Recebido para publicação em outubro de 2008 e aprovado em julho de 2009.

(2) Pós-Doutora pelo Departamento de Ciências Exatas, Escola Superior de Agricultura "Luiz de Queiroz" - ESALQ/USP. Caixa Postal 9, Av. Pádua Dias 11, CEP 13418-900 Piracicaba (SP). E-mail: flcsfernandes@gmail.com

(3) Professor Titular, Departamento de Ciências Exatas, ESALQ-USP. E-mail: pllibard@esalq.usp.br
} 
braquiária e pousio e de 56,6 a 87,4 \% do total de 419 mm de precipitação pluvial no segundo cultivo de milho. A lixiviação de $\mathrm{NO}_{3}{ }^{-}$total (do fertilizante e outras fontes) foi muito baixa no primeiro cultivo de milho em todas as doses de $\mathrm{N}$ e significativa para as doses de 120 e $180 \mathrm{~kg} \mathrm{ha}^{-1}$ nos períodos da cultura de braquiária mais pousio $\left(26,16 \mathrm{~kg} \mathrm{ha}^{-1}\right.$ para a dose de 120 e $39,8 \mathrm{~kg} \mathrm{ha}^{-1}$ para a de $\left.180 \mathrm{~kg} \mathrm{ha}^{-1}\right)$ e da segunda cultura de milho (aproximadamente $23 \mathrm{~kg} \mathrm{ha}^{-1}$ para ambas as doses). A lixiviação de $\mathrm{NO}_{3}{ }^{-}$proveniente do fertilizante foi praticamente nula no primeiro cultivo de milho e, em geral, baixa durante o cultivo de braquiária e o segundo cultivo de milho.

Termos de indexação: densidade de fluxo, ${ }^{15} \mathrm{~N}$-sulfato de amônio, plantio direto.

\title{
SUMMARY: INTERNAL DRAINAGE AND NITRATE LEACHING IN A TYPIC HAPLUDOXUNDER A MAIZE-BRACHIARIA-MAIZE SUCCESSION AT DIFFERENT NITROGEN FERTILIZER RATES
}

\begin{abstract}
The ideal $N$ fertilization should be defined to satisfy the crop needs, but with minimum environmental risk. For this purpose, $N$ fertilizer recommendations must be as accurate as possible. This study was carried out in a sand-clay soil (22 $42^{\prime} 30^{\prime \prime} \mathrm{S} ; 47^{\circ} 38^{\prime} 00$ ” W; $546 \mathrm{~m}$ asl) and the objective was to evaluate the internal drainage and nitrate leaching during the cycles of three crops in succession under no-tillage at a soil depth of $0.80 \mathrm{~m}$, using different doses of ${ }^{15} \mathrm{~N}$-labeled ammonium sulphate. The crop succession consisted of: maize in 2006 followed by brachiaria plus fallow and finally maize in 2007. Labeled N fertilizer rates of 60, 120 and $180 \mathrm{~kg} \mathrm{ha}^{-1}$ and a control (no N) were tested. The labeled fertilizer was applied to previously defined subplots, only to maize in 2006. Internal drainage was derived from the soil-water flux density calculated by the Darcy-Buckingham equation in which the hydraulic conductivity and total water potential gradient were estimated based on daily readings of $\mathrm{Hg}$ tensiometers at depths of $0.70,0.80$ and $0.90 \mathrm{~m}$. The hydraulic conductivity was determined in the field as a function of soil-water matric potential at a depth of $0.80 \mathrm{~m}$, by the instantaneous profile method, using tensiometers and soil-water retention curves. The soil-water flux density was also used, together with nitrate concentration and the ${ }^{15} \mathrm{~N}$ atom $\%$ in soil solution, to estimate nitrate leaching of both total and fertilizer nitrate. Internal drainage decreased with the increase of applied $N$ levels to the crop succession, changing from 31.5 to $73.4 \%$ of the total rainfall $(97 \mathrm{~mm})$ in the first maize, from 26.1 to $58.1 \%$ of the total rainfall $(695 \mathrm{~mm})$ in brachiaria + fallow, and from 56.6 to $87.4 \%$ of the $419 \mathrm{~mm}$ of total rainfall in the second maize crop. The leaching of total nitrate (from fertilizer and other sources) was very low in the first maize crop for all applied N levels and significant for the rates of 120 and $180 \mathrm{~kg} \mathrm{ha}^{-1}$ in the periods of brachiaria plus fallow (26.16 for $120 \mathrm{~kg} \mathrm{ha}^{-1}$ and 39.8 for $180 \mathrm{~kg} \mathrm{ha}^{-1}$ ) and of the second maize crop (approximately $23 \mathrm{~kg} \mathrm{ha}^{-1}$ for both levels). There was no $\mathrm{N}$ leaching from fertilizer in the first maize crop and N leaching was very low in the brachiaria and second maize crop.
\end{abstract}

Index terms: flux density; $15 \mathrm{~N}$ - ammonium sulphate; no-till farming.

\section{INTRODUÇÃO}

O milho é uma das culturas mais exigentes em fertilizantes, especialmente os nitrogenados. O suprimento inadequado de $\mathrm{N}$ é considerado um dos principais fatores limitantes ao seu rendimento de grãos. Analisando os dados obtidos em 170 experimentos realizados em Minas Gerais, França et al. (1985) relataram que em $99 \%$ dos ensaios o milho houve resposta positiva à adubação nitrogenada.
Resultados, incluindo médias de diversos experimentos, mostram respostas à aplicação de até $120 \mathrm{~kg} \mathrm{ha}^{-1}$ de N. Para o Estado de São Paulo, a aplicação de $\mathrm{N}$ em milho é baseada somente na expectativa do rendimento de grãos. No Sul do Brasil, a recomendação de adubação nitrogenada na cultura do milho é baseada no teor de matéria orgânica (MO) no solo, na expectativa de rendimento de grãos e no histórico de utilização da área (Amado et al., 2002). No entanto, existem vários outros fatores que poderão 
interferir na resposta do milho à aplicação de $\mathrm{N}$ em semeadura direta, que deveriam ser levados em consideração na recomendação de adubação desse nutriente. Entre esses fatores, destacam-se a disponibilidade inicial de $\mathrm{N}$ no solo, o tipo de sequência de culturas em sucessão, o sistema de rotação de culturas e o tempo de adoção do sistema semeadura direta (Sá, 1996). Amado et al. (2002) recomendam a adubação nitrogenada com base no teor de MO do solo e na expectativa do rendimento de grãos de milho e também propõe um terceiro critério, que é a contribuição em N mineralizado de culturas de cobertura antecedentes.

Outro aspecto a ser considerado seria o ambiental, ou seja, suprir a planta nos períodos críticos, mas também minimizar o impacto ambiental por meio da redução de perdas como imobilização, volatilização, desnitrificação e lixiviação, as quais são as grandes responsáveis pela baixa eficiência do uso de fertilizantes nitrogenados (Ivanko, 1972). De acordo com Moreira \& Siqueira (2002), a desnitrificação e a lixiviação são os principais processos de perda de $\mathrm{N}$ do solo e, juntos, contribuem com $72 \%$ dessa perda. Sexton et al. (1996) observaram que o $\mathrm{NO}_{3}{ }^{-}$lixiviado aumentou rapidamente quando as doses de $\mathrm{N}$ excederam $100 \mathrm{~kg} \mathrm{ha}^{-1}$, para crescimento de milho sob um solo arenoso, e que, para doses de $\mathrm{N}$ acima de $250 \mathrm{~kg} \mathrm{ha}^{-1}$ (correspondendo ao máximo rendimento), o $\mathrm{NO}_{3}^{-}$lixiviado aumentou exponencialmente. Segundo Hoeft (2003), a dose, a época e o método de aplicação de fertilizantes nitrogenados têm efeito marcante tanto sobre a produtividade das culturas como sobre o potencial de contaminação dos mananciais de água subterrânea pelos nutrientes. Quanto mais cedo o $\mathrm{N}$ for aplicado, antes da época na qual a cultura precisa dele, e quanto maior for a dose aplicada, maior será a quantidade de $\mathrm{N}$ perdida. Entretanto, a quantidade de $\mathrm{N}$ que se perde por lixiviação também varia grandemente em função da velocidade de mineralização e imobilização por plantas e microrganismos (Moreira \& Siqueira, 2002), da precipitação pluvial (Fernandes et al., 2006) e das propriedades do solo que influenciam a capacidade de retenção de água, ou seja, a textura, a estrutura e a porosidade (Kiehl, 1987).

Nesse contexto, este trabalho teve por objetivo avaliar a drenagem interna e a lixiviação de $\mathrm{NO}_{3}{ }^{-}$ (total e daquele proveniente do fertilizante) na profundidade de $0,80 \mathrm{~m}$ em uma sucessão de culturas (milho-braquiária-milho), utilizando-se sulfato de amônio marcado com ${ }^{15} \mathrm{~N}$ e com diferentes doses de $\mathrm{N}$.

\section{MATERIAL E MÉTODOS}

O experimento foi conduzido, sob condições de campo, na área experimental da Escola Superior de Agricultura Luiz de Queiroz, Universidade de São Paulo, cujas coordenadas geográficas são $22^{\circ} 42$ ' 30 ” de latitude sul, $47^{\circ} 38^{\prime} 00$ " de longitude oeste e, aproximadamente, $546 \mathrm{~m}$ de altitude. Segundo a classificação de Köppen, o clima é do tipo Cwa, denominado "tropical de altitude". É um clima mesotérmico de inverno seco, em que a temperatura média do mês mais frio é inferior a $18^{\circ} \mathrm{C}$ e a do mês mais quente ultrapassa $22^{\circ} \mathrm{C}$. As médias anuais de temperatura, precipitação pluvial e umidade relativa são de $21,1^{\circ} \mathrm{C}, 1.257 \mathrm{~mm}$ e $74 \%$, respectivamente. A estação seca ocorre entre os meses de abril e setembro, sendo julho o mês mais seco. $\mathrm{O}$ mês mais chuvoso oscila entre janeiro e fevereiro, e as chuvas mensais do período de abril a setembro (série histórica de 1917 a 1998) variam de $23 \mathrm{~mm}$ no mês de julho a $52 \mathrm{~mm}$ no mês de abril; nesse período, a evapotranspiração potencial média mensal é de $61 \mathrm{~mm}$ (Sentelhas et al., 2008). O experimento foi monitorado quanto a precipitação pluvial e temperaturas máxima e mínima diárias (Figura 1).

O solo do local é um Latossolo Vermelho-Amarelo distrófico (Embrapa, 2006) ou Typic Hapludox (Soil Survey Staff, 2003). Antes da implantação do experimento foram coletadas amostras de solo das camadas de $0-0,2,0,2-0,4,0,4-0,6$ e $0,6-0,8 \mathrm{~m}$, para determinação de características químicas e físicas do perfil (Quadros 1 e 2). A análise granulométrica foi realizada de acordo com o método descrito em Gee \& Bauder (1986); a determinação da densidade do solo (método do anel volumétrico), da densidade das partículas (método do balão volumétrico) e das porosidades foi realizada conforme descrito em Kiehl (1979). O experimento envolveu dois cultivos de milho - o primeiro na safrinha 2006 e o segundo na safrinha 2007 - e um cultivo de braquiária na entressafra. A área estava sob uso de semeadura direta há três anos.

O delineamento experimental foi em blocos aleatorizados e consistiu na aplicação de quatro doses de N, na forma de sulfato de amônio $(0,60,120$ e $180 \mathrm{~kg} \mathrm{ha}^{-1}$ de N), com quatro repetições, numa sucessão de culturas (milho-braquiária-milho). A

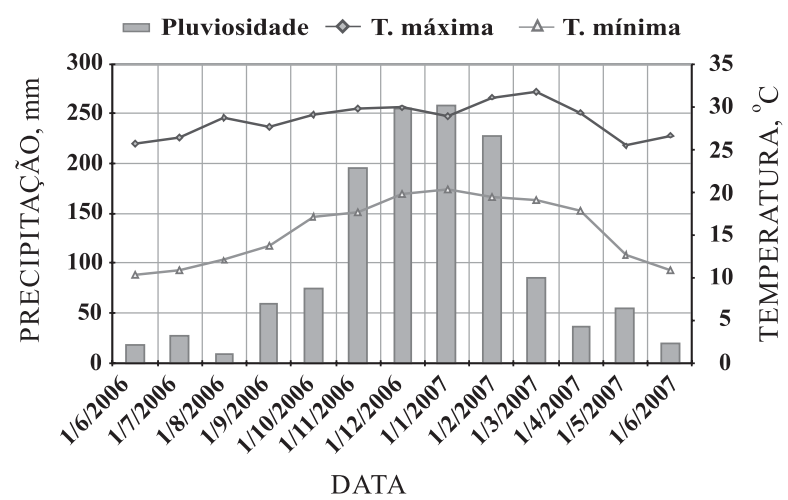

Figura 1. Dados pluviométricos e de temperaturas máxima e mínima (média mensal) ocorridos durante a condução dos experimentos - anos agrícolas 2006 e 2007. 
Quadro 1. Propriedades químicas ${ }^{(1)}$ do solo antes da instalação do experimento, em diferentes camadas do solo

\begin{tabular}{|c|c|c|c|c|c|c|c|c|}
\hline Camada & pH $\mathrm{CaCl}_{2}$ & MO & P-resina & $\mathbf{K}$ & $\mathrm{Ca}^{2+}$ & $\mathrm{Mg}^{2+}$ & $\mathbf{H}+\mathbf{A l}$ & $\mathrm{Al}^{3+}$ \\
\hline $\mathrm{m}$ & & $\mathrm{g} \mathrm{dm} \mathrm{m}^{-3}$ & $\mathrm{mgdm} \mathrm{m}^{-3}$ & 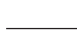 & 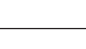 & $\mathrm{mmol}_{\mathrm{c}} \mathrm{d}$ & & - \\
\hline $0-0,2$ & 4,77 & 20 & 10,00 & 1,61 & 16 & 13 & 31 & 2,0 \\
\hline $0,2-0,4$ & 4,06 & 18 & 6,66 & 1,12 & 9 & 5 & 40 & 4,0 \\
\hline $0,4-0,6$ & 3,61 & 11 & 1,48 & 0,91 & 6 & 1 & 50 & 11,4 \\
\hline $0,6-0,8$ & 3,87 & 11 & 2,22 & 0,63 & 10 & 2 & 313 & 7,1 \\
\hline
\end{tabular}

(1) Métodos descritos em Raij et al. (2001).

Quadro 2. Densidade de partículas $\left(\rho_{\mathrm{s}}\right)$, análise granulométrica/classe textural, densidade do solo( $\left.\rho\right)$ e porosidade do solo, antes da instalação do experimento, em diferentes camadas do solo

\begin{tabular}{|c|c|c|c|c|c|c|c|c|c|}
\hline \multirow{2}{*}{ Camada } & \multirow{2}{*}{$\rho_{\mathrm{s}}$} & \multirow{2}{*}{ Areia } & \multirow{2}{*}{ Silte } & \multirow{2}{*}{ Argila } & \multirow{2}{*}{ Classe textural } & \multirow{2}{*}{$\rho$} & \multicolumn{3}{|c|}{ Porosidade } \\
\hline & & & & & & & Total & Macro & Micro \\
\hline $\mathrm{m}$ & $\mathrm{kg} \mathrm{m}^{-3}$ & 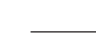 & $\mathrm{g} \mathrm{kg}^{-1}$ & - & & $\mathrm{kg} \mathrm{m}^{-3}$ & 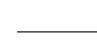 & — & - \\
\hline $0-0,2$ & 2.754 & 840 & 20 & 140 & Areia franca & 1.627 & 40,91 & 12,94 & 27,97 \\
\hline $0,2-0,4$ & 2.760 & 800 & 20 & 180 & Franco-arenosa & 1.678 & 39,19 & 13,11 & 26,07 \\
\hline $0,4-0,6$ & 2.738 & 760 & 40 & 200 & Franco-argiloarenosa & 1.675 & 38,81 & 12,71 & 26,10 \\
\hline $0,6-0,8$ & 2.693 & 760 & 40 & 200 & Franco-argiloarenosa & 1.635 & 39,29 & 12,73 & 27,22 \\
\hline
\end{tabular}

aplicação foi parcelada, sendo $30 \mathrm{~kg} \mathrm{ha}^{-1}$ de $\mathrm{N}$ na semeadura e o restante em cobertura, no estádio de 6 a 8 folhas. Cada parcela experimental consistiu de uma área de $36 \mathrm{~m}^{2}$ (5,0 x 7,2 m), com nove linhas de milho espaçadas em $0,80 \mathrm{~m}$, sendo a distância entre parcelas de $2,0 \mathrm{~m}$. A subparcela do ${ }^{15} \mathrm{~N}$ foi demarcada a 1,5 $\mathrm{m}$ da extremidade da parcela, com as dimensões de 2,0 x 2,4 m (4,8 $\left.\mathrm{m}^{2}\right)$, para aplicação do sulfato de amônio enriquecido com 5,5\% de átomos de ${ }^{15} \mathrm{~N}$. No restante da área da parcela foi aplicado, como fonte de $\mathrm{N}$, sulfato de amônio não enriquecido com ${ }^{15} \mathrm{~N}$.

O cultivar de milho usado nos anos agrícolas 2006 e 2007 foi o DKB350, híbrido simples, ciclo precoce, plantio normal, utilizado para produção de grãos e altamente resistente ao acamamento. As semeaduras foram realizadas manualmente em 26/4/2006 e 12/2/ 2007 para primeiro e segundo cultivos, respectivamente. As sementes foram distribuídas com auxílio de uma régua, deixando-se, a cada 0,20 m, duas sementes, desbastando-se para uma planta, duas semanas após a emergência, para obtenção de uma população final de aproximadamente 62.500 plantas por hectare, ou seja, cinco plantas por metro linear. A adubação básica (fosfatada e potássica), no sulco de semeadura, foi realizada em ambos os cultivos de milho na dose de $90 \mathrm{~kg} \mathrm{ha}^{-1} \mathrm{de}_{2} \mathrm{O}_{5}$ e $50 \mathrm{~kg} \mathrm{ha}^{-1}$ de $\mathrm{KCl}$ (Raij et al., 1997), na forma de superfosfato simples e cloreto de potássio, respectivamente, aplicados a $0,05 \mathrm{~m}$ ao lado e abaixo das sementes no momento da semeadura, para evitar o contato direto com estas. As adubações nitrogenadas tiveram como fonte o sulfato de amônio e foram realizadas manualmente, no sulco de semeadura (adubação plantio), e incorporadas em sulco superficial a 0,20 m da linha da cultura (adubação de cobertura), quando as plantas de milho se encontravam no estádio de 6-8 folhas totalmente desdobradas. A aplicação do sulfato de amônio enriquecido com ${ }^{15} \mathrm{~N}$ foi feita, manualmente, apenas no primeiro cultivo do milho nas linhas de plantio das subparcelas (adubação de plantio); quando da adubação de cobertura, o adubo foi incorporado em sulco a $0,20 \mathrm{~m}$ da linha de semeadura. As plantas de milho atingiram o florescimento pleno em 1/08/2006 (primeiro cultivo) e 1/5/2007 (segundo cultivo). A colheita de grãos do primeiro cultivo foi em 26/9/2006, e a do segundo, em 18/6/2007. Após a colheita da cultura do milho, realizou-se o manejo mecânico com roçadeira lateral de três facas.

A braquiária foi semeada em linha em 9/10/2006. Para semear a braquiária, foi feita a retirada de toda a palhada do milho, demarcaram-se as linhas espaçadas de $0,20 \mathrm{~m}$, empregando-se uma densidade de sementes de $13 \mathrm{~kg} \mathrm{ha}{ }^{-1}$, e posteriormente retornouse a palhada na parcela. As plantas atingiram o florescimento pleno em 30/12/2006. Na época do florescimento das plantas foi aplicado o herbicida glifosato $\left(3 \mathrm{~L} \mathrm{ha}^{-1}\right)$ e, posteriormente, realizado o manejo mecânico com roçadeira lateral de três facas. 


\section{Caracterização hídrica do solo}

Antes do plantio, foi realizada a caracterização hídrica do solo por meio da determinação das curvas de retenção da água no solo. Coletaram-se amostras com estrutura indeformada ao longo do perfil, em uma trincheira adjacente à parcela experimental. Os anéis volumétricos de coleta apresentavam um volume, em média, de $2,55 \times 10^{-3} \mathrm{~m}^{3}(0,052 \mathrm{~m}$ de altura $\mathrm{x} 0,049 \mathrm{~m}$ de diâmetro). Foram retiradas 10 amostras de cada uma das seguintes profundidades: 0,$1 ; 0,2 ; 0,3 ; 0,4$; 0,$5 ; 0,6 ; 0,7 ; 0,8 ; 0,9 ;$ e $1,0 \mathrm{~m}$, perfazendo um total de 100 amostras. Utilizou-se amostrador do tipo Uhland. As amostras foram adequadamente acondicionadas, levadas para o laboratório, preparadas e colocadas para saturação; posteriormente, foram submetidas às tensões de 0,$5 ; 1,0 ; 3,0 ; 5,0 ; 10 ; 50$; e $100 \mathrm{kPa}$, para determinação das curvas de retenção. Foram utilizados funis de Haines para baixas tensões $(0,5$; 1,$0 ; 3,0 ; 5,0$; e $10 \mathrm{kPa}$ ) e câmaras de pressão de Richards para altas tensões (50 e $100 \mathrm{kPa}$ ), conforme procedimentos descritos por Libardi (2005).

Para determinação da condutividade hidráulica do solo sob condição de não saturação, pelo método do perfil instantâneo, no campo (Libardi, 2005), foi utilizada uma estrutura de chapa galvanizada de espessura de $2 \mathrm{~mm}, 1,2 \mathrm{~m}$ de altura e 2,5 $\mathrm{m}$ de raio, que foi introduzida no solo até a profundidade de $1,0 \mathrm{~m}$, a fim de criar uma lâmina de $0,2 \mathrm{~m}$ e evitar o fluxo lateral de água quando da inundação e durante a redistribuição. No centro da coluna de solo delimitada, foram instalados tensiômetros nas profundidades de 0,$1 ; 0,2 ; 0,3 ; 0,4 ; 0,5 ; 0,6 ; 0,7 ; 0,8 ; 0,9 ; 1,0 ;$ e $1,1 \mathrm{~m}$. $\mathrm{O}$ perfil foi saturado colocando-se água com auxílio de um caminhão-pipa, até que se umedecesse o máximo possível a camada de 0-1,1 m do solo. Posteriormente, a parcela foi coberta com uma capa plástica para evitar qualquer fluxo de água pela superfície do solo. O momento da colocação do plástico foi considerado o tempo zero $(\mathrm{t}=0)$ de redistribuição; a partir daí, iniciaram-se as leituras dos tensiômetros até quando a drenagem se tornasse praticamente nula (14 dias), o que era verificado pela estabilização das leituras. A condutividade hidráulica $(K)$ em função do potencial mátrico $\phi_{\mathrm{m}}$ foi determinada a partir da equação (1), utilizando o procedimento de Hillel et al. (1972), com os dados de conteúdo de água no perfil obtidos a partir das leituras dos tensiômetros e das curvas de retenção determinadas nas mesmas profundidades:

$$
\left.K\right|_{Z}=\frac{-\int_{0}^{Z} \frac{\partial \theta}{\partial t} d Z}{\left.\frac{\partial \phi_{t}}{\partial z^{*}}\right|_{Z}}
$$

em que $t$ é o tempo de redistribuição; $Z$, a profundidade do solo; $\phi_{t}$, o potencial total da água no solo; $\theta$, o conteúdo de água volumétrico; e $z^{*}$, a coordenada vertical de posição.
A equação obtida para a função $K\left(\phi_{m}\right)$, para a profundidade de $0,80 \mathrm{~m}$, foi:

$$
K=e^{7,0145 \phi \mathrm{m}-1,588}
$$

em que $K$ é expressa em mm dia ${ }^{-1}$ e $\phi_{m}$ em m de água.

\section{Fluxo de água no solo}

$\mathrm{Na}$ linha central das subparcelas com ${ }^{15} \mathrm{~N}$, foram instalados tensiômetros com manômetro de mercúrio nas profundidades de 0,70, 0,80 e 0,90 m. As leituras dos tensiômetros foram realizadas diariamente ao longo do ciclo das culturas. A partir das leituras dos tensiômetros nas profundidades de 0,70 e $0,80 \mathrm{~m}$ foram determinados os gradientes de potencial total $\left(\Delta \Phi t / \Delta z^{*}\right)$, em $Z=0,80 \mathrm{~m}$; com as leituras dos tensiômetros a $0,80 \mathrm{~m}$ de profundidade, foi calculada a condutividade hidráulica $(K)$, em $Z=0,80 \mathrm{~m}$. Com os valores diários de $K$ e $\Delta \Phi t / \Delta z^{*}$ calculou-se a densidade de fluxo de água (q) na profundidade $Z=0,80 \mathrm{~m}$, segundo a equação (3) de Darcy-Buckingham (Libardi, 2005).

$$
q=-K \frac{\Delta \phi_{t}}{\Delta z^{*}}
$$

O potencial total em cada profundidade foi calculado pela equação (4):

$$
\phi_{t}=\phi_{m}=\phi_{g}
$$

em que $\phi_{g}$ é o potencial gravitacional, em $m$ de água.

O potencial mátrico $\phi_{m}$, em $m$ de água, foi calculado de acordo com a eq. (5):

$$
\phi_{m}=12,6 H+h c+Z
$$

em que $H=$ leitura realizada no manômetro, em $\mathrm{m}$ $\mathrm{Hg} ; h_{c}=$ altura do nível de mercúrio na cuba em relação à superfície do solo, em m de água; e $Z$ = profundidade de instalação dos tensiômetros, em m de água.

\section{Lixiviação de nitrato da solução no solo}

$\mathrm{Na}$ linha central das subparcelas com ${ }^{15} \mathrm{~N}$, foi instalado, juntamente com os tensiômetros, um extrator da solução no solo na profundidade de $0,80 \mathrm{~m}$. A solução era retirada fazendo-se vácuo por meio de uma bomba manual, até que se observasse no manômetro uma leitura de 430-480 kPa. Esse vácuo era mantido fechando-se o tubo de conexão entre o extrator e a bomba de vácuo e, depois de um tempo mínimo de $4 \mathrm{~h}$ (em função do conteúdo de água no solo), a solução era retirada. O conteúdo de água no solo permitiu coleta de solução nos dias 2 de julho; 30 de novembro; 10,25 e 31 de dezembro de 2006; e 1 o e 24 de janeiro, 9 e 21 de fevereiro, 20 de março e 27 de maio de 2007. Depois de coletadas, as amostras eram congeladas e posteriormente analisadas no sistema FIA - Flow Injection Analysis, segundo os procedimentos descritos em Gine et al. (1980). Assim, 
as concentrações de $\mathrm{N}-\mathrm{NO}_{3}{ }^{-}\left(\mathrm{C}_{N O_{3}}{ }^{-}\right)$da solução no solo foram determinadas em $\mathrm{mg} \mathrm{L}^{-1}$. A densidade de fluxo de $\mathrm{NO}_{3}^{-}$(lixiviação) na profundidade $\mathrm{Z}=0,80 \mathrm{~m}$ foi determinada pelo produto da densidade de fluxo de água $(q)$ e a concentração de $\mathrm{NO}_{3}\left(\mathrm{~kg} \mathrm{~L}^{-1}\right.$ de solução) da solução extraída do solo com o extrator, isto é:

$$
q_{\mathrm{NO}_{3}}^{-}=q \times \mathrm{C}_{\mathrm{NO}_{3}}{ }^{-}
$$

sendo $q_{\mathrm{NO}_{3}}\left(\mathrm{~kg} \mathrm{ha}^{-1} \mathrm{dia}^{-1}\right)=$ densidade de fluxo de $\mathrm{NO}_{3}{ }^{-}$ no solo à profundidade de $0,80 \mathrm{~m}$ num dado instante; e $\mathrm{C}_{N O_{3}}\left(\mathrm{~kg} \mathrm{~L}^{-1}\right)=$ concentração média (por tratamento) de $\mathrm{NO}_{3}^{-}$da solução no solo no mesmo instante e profundidade.

Para a determinação de $\mathrm{N}-\mathrm{NO}_{3}{ }^{-}$da solução no solo proveniente do fertilizante (NSSPF), as amostras foram destiladas num sistema micro-Kjeldahl, baseificando-se a solução com $\mathrm{MgO}$, sendo o destilado recolhido em solução de $\mathrm{H}_{3} \mathrm{BO}_{3}\left(20 \mathrm{~g} \mathrm{~L}^{-1}\right)$ e posteriormente titulado com $\mathrm{H}_{2} \mathrm{SO}_{4} 0,05 \mathrm{~mol} \mathrm{~L}^{-1}$ (Trivelin et al., 1973). As determinações de ${ }^{15} \mathrm{~N}$ das amostras destiladas da solução no solo foram realizadas em espectrômetro de massa de setor magnético com ionização por impacto de elétrons IRMS - ATLAS MAT $\mathrm{CH}_{4}$ (Trivelin et al., 1973). Com os resultados, foram determinadas as concentrações de nitrato derivado do fertilizante $\left(\mathrm{C}_{\mathrm{nf}}\right)$, de acordo com a equação (7):

$$
C_{n f}=\frac{\% N S S P F}{100} \times C_{\mathrm{NO}_{3}^{-}}
$$

sendo \%NSSPF a percentagem de $\mathrm{NO}_{3}{ }^{-}$da solução no solo proveniente do fertilizante.

Os dados foram submetidos à análise de variância e comparação de médias pelo teste de Tukey $(p=0,05)$.

\section{RESULTADOS E DISCUSSÃO}

As densidades de fluxo de água (Figuras 2 e 3), na profundidade de $0,80 \mathrm{~m}$, foram monitoradas diariamente durante o primeiro (safra 2006) e segundo (safra 2007) ciclos de milho e o ciclo da braquiária (safra 2006). Os valores negativos nessas figuras indicam drenagem interna, e os positivos (muito raros), ascensão capilar.

No primeiro e segundo cultivos de milho safrinha, as precipitações totalizaram 96,8 e $418,9 \mathrm{~mm}$, respectivamente. A precipitação pluvial ocorrida no período de cultivo do milho safrinha do ano de 2006 apresentou-se muito inferior ao mínimo indicado (400 $500 \mathrm{~mm}$ ) por Fancelli \& Dourado Neto (2005), o que levou a um baixo rendimento de grãos de milho (904, $1.494,2.167$ e $1.858 \mathrm{~kg} \mathrm{ha}^{-1}$ para as doses de 0,60 , 120 e $180 \mathrm{~kg} \mathrm{ha}^{-1}$ de N, respectivamente). Segundo esses autores, esse limite de precipitação indicado é o suficiente para que a cultura produza a contento, sem a necessidade da prática de irrigação. Já para o cultivo de milho safrinha de 2007, a precipitação pluvial total

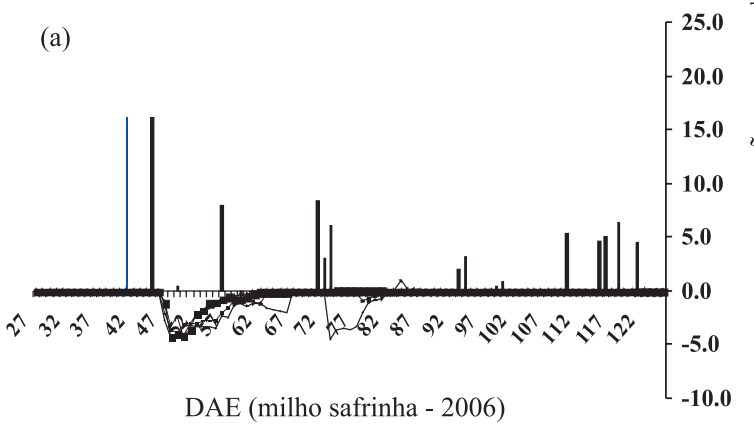

(b)

- Precipitação $\rightarrow 0 \mathrm{~kg} \mathrm{ha}^{-1} \rightarrow 60 \mathrm{~kg} \mathrm{ha}^{-1}$ $+120 \mathrm{~kg} \mathrm{ha}^{-1} * 180 \mathrm{~kg} \mathrm{ha}^{-1}$

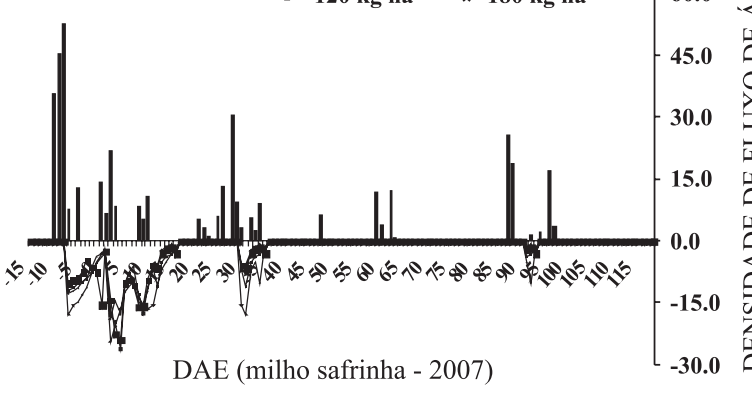

Figura 2. Densidade de fluxo de água e precipitação pluvial em função do tempo (DAE = dias após a emergência), na cultura de milho safrinha, ano 2006 (a) e 2007 (b), nos tratamentos 0, 60, 120 e $180 \mathrm{~kg} \mathrm{ha}^{-1}$.

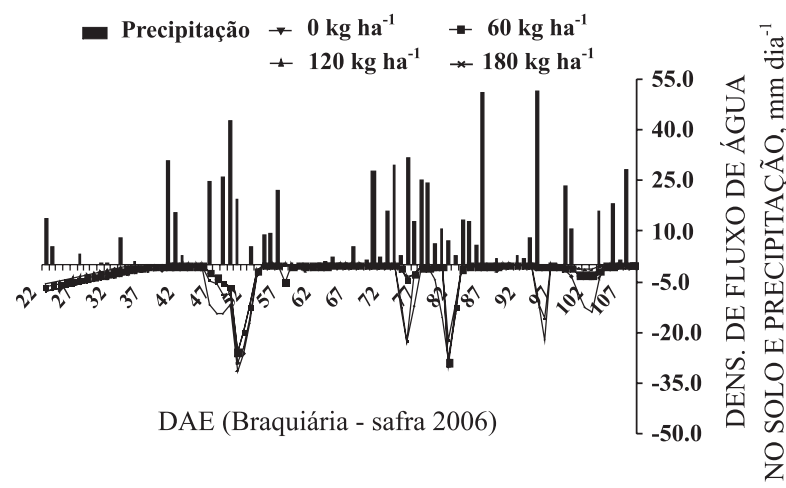

Figura 3. Densidade de fluxo de água e precipitação pluvial em função do tempo (DAE = dias após a emergência), na cultura da braquiária, safra 2006 , nos tratamentos $0,60,120$ e $180 \mathrm{~kg} \mathrm{ha}^{-1}$.

não foi problema, pois estava dentro do referido limite, porém a má distribuição de chuva pode ter sido uma das responsáveis pelo baixo rendimento de grãos de milho $\left(1.279,2.117,3.186\right.$ e $3.097 \mathrm{~kg} \mathrm{ha}^{-1}$ para as doses de $0,60,120$ e $180 \mathrm{~kg} \mathrm{ha}^{-1}$ de $\mathrm{N}$, respectivamente).

Para o primeiro cultivo de milho (Figura 2a), a baixa precipitação pluvial originou baixas densidades de fluxo de água, menores que $4 \mathrm{~mm} \mathrm{dia}^{-1}$, para todos os tratamentos estudados. Em consequência da precipitação pluvial, altas densidades de fluxo de água 
foram obtidas no segundo cultivo de milho (Figura 2b), entre a emergência e a segunda adubação nitrogenada (37 DAE), com médias de $6,97,5,64,4,45$ e $5,36 \mathrm{~mm} \mathrm{dia}^{-1}$, máximas de $24,35,17,69,18,67 \mathrm{e}$ $14,29 \mathrm{~mm} \mathrm{dia}^{-1} \mathrm{e}$ uma drenagem interna de 250,94 , $203,40,160,22$ e 193,08 $\mathrm{mm}$ para os tratamentos em que se aplicaram $0,60,120$ e $180 \mathrm{~kg} \mathrm{ha}^{-1} \mathrm{de} \mathrm{N}$, respectivamente. Em compensação, após $38 \mathrm{DAE}$, a precipitação foi baixa, gerando também baixas densidades de fluxo de água. Gava (2003) observou valores de drenagem interna de $188 \mathrm{~mm}$ para cultivo de milho sob plantio direto e $38 \mathrm{~mm}$ sob plantio convencional, os quais foram bem abaixo dos dados aqui encontrados (Quadros 3 e 5). Entretanto, Fernandes et al. (2006), trabalhando nessa mesma área com parcelamentos de $\mathrm{N}$ em milho, na implantação do sistema plantio direto, obtiveram resultados médios de $467 \mathrm{~mm}$ de drenagem interna no período de cultivo. No entanto, Castro et al. (2002), trabalhando em um solo argiloarenoso sob diferentes condições de manejo, encontraram resultados próximos ao deste experimento. Segundo esses autores, as maiores densidades de fluxo de água foram de $40 \mathrm{~mm} \mathrm{dia}{ }^{-1} \mathrm{em}$ solo sob pastagem e cultivo convencional, de $25 \mathrm{~mm} \mathrm{dia}^{-1}$ sob plantio direto e de $180 \mathrm{~mm}$ dia $^{-1}$ sob solo nu. A explicação para a obtenção de altas densidades de fluxo de água pode ser a textura do solo em estudo, a qual foi classificada como arenosa, pois, de maneira geral, esses solos têm menor capacidade de retenção de água e nutrientes e maior suscetibilidade à erosão e lixiviação do que os solos argilosos (Lima \& Lima, 2000).

Já para o ciclo da braquiária, safra 2006 (Figura 3), observou-se um total de $439,90 \mathrm{~mm}$ de precipitação pluvial, distribuída regularmente; $55 \%$ do total ficou entre a emergência e o início do florescimento (64 DAE); e os $45 \%$ restantes ocorreram entre o início do florescimento e o florescimento pleno (80 DAE). Assim, as densidades de fluxo de água alcançaram valores máximos de 31,48, 28,97, 25,61 e $25,68 \mathrm{~mm} \mathrm{dia}^{-1}$ e uma drenagem interna no ciclo da cultura de $307,54,240,61,161,45$ e $175,81 \mathrm{~mm}$, respectivamente, para os tratamentos de $0,60,120 \mathrm{e}$ $180 \mathrm{~kg} \mathrm{ha}^{-1}$. A distribuição regular de chuva durante o ciclo da braquiária pode ter sido a responsável pela boa quantidade de massa da matéria seca da cultura obtida, que variou de 2.500 a $5.500 \mathrm{~kg} \mathrm{ha}^{-1}$, dependendo da dose de $\mathrm{N}$ aplicada.

Quanto aos resultados para densidade de fluxo de água, houve diferença entre os tratamentos nos dois cultivos de milho e no cultivo de braquiária. Entretanto, tiveram o mesmo comportamento, ou seja, as maiores densidades de fluxo foram observadas logo após as chuvas intensas, já que as densidades de fluxo de água no solo dependem desse agente climático. Para os dois cultivos de milho (Figura 2), os tratamentos nos quais não se aplicou $\mathrm{N}$ e aqueles em que foram aplicados $60 \mathrm{~kg} \mathrm{ha}^{-1}$ de $\mathrm{N}$ apresentaram maiores densidades de fluxo de água durante todo o ciclo. Os menores valores de densidade de fluxo foram encontrados nos tratamentos em que se aplicaram 120 e $180 \mathrm{~kg} \mathrm{ha}^{-1}$ de $\mathrm{N}$ na cultura, e estes diferiram apenas do tratamento em que não se aplicou N. Isso pode ser devido, provavelmente, ao maior desenvolvimento de raízes nesses tratamentos, interferindo (aumentando) a absorção de água pelas plantas, auxiliando o maior desenvolvimento vegetativo e, assim, evitando que a água drene. Segundo Bull (1993), o aumento do rendimento proporcionado pelo $\mathrm{N}$ pode ser atribuído, também, aos efeitos deste sobre o crescimento do sistema radicular. Já para o ciclo da braquiária + pousio (Figura 3), a maior densidade de fluxo foi obtida no tratamento em que não se aplicou $\mathrm{N}$ no milho, diferindo significativamente de todos os outros. As maiores doses de $\mathrm{N}$ aplicadas no milho (120 e $180 \mathrm{~kg} \mathrm{ha}^{-1}$ ) proporcionaram maior crescimento vegetativo das plantas de braquiária, acarretando, portanto, menor densidade de fluxo, devido à quantidade de matéria seca que cobriu o solo, evitando assim o escorrimento subsuperficial.

Verificou-se também que as densidades de fluxo total de água para os tratamentos de 0,60, 120 e $180 \mathrm{~kg} \mathrm{ha}^{-1}$ de $\mathrm{N}$, ocorridas no segundo cultivo (Figura $2 \mathrm{~b}$ ), foram maiores que as do primeiro ciclo (Figura 2a), pelo fato de a precipitação pluvial, nesse período, ter sido maior. No entanto, no período de 60 123 DAE do primeiro cultivo de milho, a precipitação pluvial menor causou maior densidade de fluxo para todos os tratamentos, quando comparada ao mesmo período (60-118 DAE) do segundo cultivo de milho (2007). Esse fato deve ter ocorrido, provavelmente, devido à formação de palhada, que, por sua vez, influenciou a retenção da água na superfície, concordando com os dados obtidos por Carvalho et al. (1999).

Para o primeiro ciclo do milho (safra 2006), verificase (Quadro 3) que ocorreram pequenos fluxos de nitrato nos primeiros 60 dias após a emergência das plantas, período no qual houve maior drenagem em relação ao segundo período (60-123 DAE) nos tratamentos em que se aplicou $\mathrm{N}$ e que resultou na lixiviação do $\mathrm{NO}_{3}{ }^{-}$. A pequena quantidade de raízes nas plantas também pode ter proporcionado maior drenagem da água e, consequentemente, um fluxo de $\mathrm{NO}_{3}{ }^{-}$no período (0$60 \mathrm{DAE}$ ), pois a precipitação pluvial nos dois períodos foi semelhante.

No período de 0-60 DAE (Quadro 3), o tratamento em que não se aplicou $\mathrm{N}$ apresentou menor lixiviação de $\mathrm{NO}_{3}^{-}\left(0,04 \mathrm{~kg} \mathrm{ha}^{-1}\right)$, diferindo dos outros, mesmo que a drenagem tenha se apresentado maior nesse tratamento. $\mathrm{O}$ resultado apresenta-se lógico, pois nesse tratamento não se aplicou $\mathrm{N}$. A pequena quantidade de $\mathrm{NO}_{3}{ }^{-}$encontrada foi proveniente, provavelmente, de outras fontes de $\mathrm{N}$ que permaneciam no solo. Os resultados semelhantes de lixiviação de $\mathrm{NO}_{3}{ }^{-}$ encontrados nos tratamentos em que se aplicaram 60, 120 e $180 \mathrm{~kg} \mathrm{ha}^{-1}$ de $\mathrm{N}$ podem ser explicados pela baixa precipitação pluvial ocorrida no período de 0-60 DAE (47,0 mm), o que consequentemente gerou baixa lixiviação de $\mathrm{N}$ aplicado. Esse fato pode ser com- 
provado pela semelhança da quantidade de $\mathrm{NO}_{3}{ }^{-} \mathrm{da}$ solução no solo proveniente do fertilizante nos tratamentos de 60, 120 e $180 \mathrm{~kg} \mathrm{ha}^{-1}(0,06,0,07$ e $0,08 \mathrm{~kg} \mathrm{ha}^{-1}$, respectivamente). Já entre 60 e 123 DAE não foi encontrado $\mathrm{NO}_{3}{ }^{-}$na solução do solo, fato esse explicado pela baixa drenagem interna medida a 0,80 m de profundidade do solo no período.

Portanto, durante o primeiro ciclo de milho (Quadro 3), 0,04, 0,27, 0,27 e 0,29 kg ha-1 de $\mathrm{NO}_{3}^{-}$(ou 0,009, 0,061, 0,061 e 0,066 kg ha-1 de N), para os tratamentos de $0,60,120$ e $180 \mathrm{~kg} \mathrm{ha}^{-1}$ respectivamente, foram lixiviados a $0,80 \mathrm{~m}$, dos quais $0,0,06,0,07 \mathrm{e}$ $0,07 \mathrm{~kg} \mathrm{ha}^{-1}$ foram provenientes do fertilizante aplicado. Esses baixos valores são devidos, provavelmente, à baixa precipitação pluvial no período em que foi cultivado o milho safrinha. Libardi \& Reichardt (1978) foram um dos pioneiros no assunto e constataram perdas de $6,7 \mathrm{~kg} \mathrm{ha}^{-1}$ de $\mathrm{N}$ durante o período de um ano na profundidade de $1,2 \mathrm{~m}$, quando se aplicou dose de $120 \mathrm{~kg} \mathrm{ha}{ }^{-1}$ de $\mathrm{N}$ na cultura do feijão. Num experimento realizado na mesma área, Fernandes et al. (2006) encontraram valor médio de $80 \mathrm{~kg} \mathrm{ha}^{-1} \mathrm{de} \mathrm{NO}_{3}^{-}$ no solo, a 0,80 $\mathrm{m}$ de profundidade, para uma precipitação pluvial de $615 \mathrm{~mm}$, quando se aplicaram $120 \mathrm{~kg} \mathrm{ha}^{-1}$ na cultura do milho. Esses autores comentam que o alto valor de $\mathrm{NO}_{3}{ }^{-}$obtido deveu-se à textura do solo (arenosa). Sogbedji et al. (2000) afirmaram também que perdas por lixiviação de $\mathrm{NO}_{3}^{-}$ foram maiores em solos arenosos do que nos argilosos. Os resultados desse atual experimento podem ser comparados aos encontrados por Gava (2003), que obteve, em experimento com milho em plantio direto, valores muito baixos de $\mathrm{N}$ lixiviado em um solo de textura argilosa. Esse autor encontrou um máximo de lixiviação de $\mathrm{N}$ de $1,5 \mathrm{~kg} \mathrm{ha}^{-1}$, a $0,50 \mathrm{~m}$, no período de 20 a 128 DAE, aplicando $25 \mathrm{~kg} \mathrm{ha}^{-1}$ de N em semeadura e $50 \mathrm{~kg} \mathrm{ha}{ }^{-1}$ de $\mathrm{N}$ em cobertura. Já Gollany et al. (2005), estudando doses de $\mathrm{N}$ em solos argilosos, encontraram valores médios de $\mathrm{NO}_{3}{ }^{-}$lixiviado de 32 e $78 \mathrm{~kg} \mathrm{ha}^{-1}$ ano $^{-1}$ quando aplicaram doses de $20 \mathrm{e}$ $200 \mathrm{~kg} \mathrm{ha}^{-1}$ de $\mathrm{N}$ em milho, respectivamente.

A lixiviação de $\mathrm{NO}_{3}{ }^{-}$no período de crescimento da braquiária (Quadro 4) mostrou diferenças entre tratamentos somente no período de cultivo de braquiária e não no de pousio. Os tratamentos em que se aplicaram 120 e $180 \mathrm{~kg} \mathrm{ha}^{-1}$ de N no milho safrinha 2006 apresentaram maiores valores de lixiviação de $\mathrm{NO}_{3}{ }^{-}$, diferindo dos outros dois. Esse fato ocorreu devido à alta quantidade de $\mathrm{N}$ aplicada no milho nesses tratamentos, o qual provavelmente não foi absorvido pelas plantas em razão da baixa ocorrência de chuva no cultivo do milho. Isso pode ser comprovado pela superioridade nos resultados da drenagem interna nos tratamentos de 0 e $60 \mathrm{~kg} \mathrm{ha}^{-1}$, quando comparada à dos tratamentos de 120 e $180 \mathrm{~kg} \mathrm{ha}^{-1}$ de N. A drenagem interna foi menor nestes tratamentos, possivelmente, devido ao maior crescimento vegetativo das plantas, ao maior consumo de água e a uma maior cobertura morta protegendo o solo. $\mathrm{O} \mathrm{NO}_{3}{ }^{-}$ proveniente do fertilizante foi maior para o tratamento em que se aplicaram $180 \mathrm{~kg} \mathrm{ha}^{-1}$ de $\mathrm{N}$, seguido do tratamento com $120 \mathrm{~kg} \mathrm{ha}^{-1}$ de $\mathrm{N}$, o que comprova a baixa absorção do $\mathrm{N}$ aplicado no primeiro cultivo (safrinha 2006), quando se utilizaram essas doses.

No período de pousio (Quadro 4), embora a drenagem interna tenha diferido significativamente entre os tratamentos, a lixiviação total de $\mathrm{NO}_{3}{ }^{-}$e o $\mathrm{NO}_{3}^{-}$proveniente do fertilizante não apresentaram diferenças. Observa-se que a maior parte dos valores de lixiviação de $\mathrm{NO}_{3}{ }^{-}$foi obtida no período de cultivo da braquiária (0-80 DAE), em consequência da precipitação pluvial e de resíduos do fertilizante da cultura anterior.

Quadro 3. Drenagem interna e lixiviação de nitrato, total (fertilizante e outras fontes) e proveniente do fertilizante (PF), a $0,80 \mathrm{~m}$ de profundidade, na cultura do milho safrinha 2006

\begin{tabular}{|c|c|c|c|c|c|}
\hline \multirow{2}{*}{ Dose de N } & \multirow{2}{*}{$\mathrm{DAE}^{(1)}$} & \multirow{2}{*}{ Precipitação } & \multirow{2}{*}{ Drenagem interna } & \multicolumn{2}{|c|}{ Lixiviação de $\mathrm{NO}_{3}^{-}$} \\
\hline & & & & Total & PF \\
\hline $\mathrm{kg} \mathrm{ha}^{-1}$ & & $\longrightarrow$ & - & $\longrightarrow$ & - \\
\hline 0 & \multirow{4}{*}{$0-60$} & \multirow{4}{*}{47,0} & $39,91 \mathrm{a}^{(2)}$ & $0,04 \mathrm{~b}$ & - \\
\hline 60 & & & $32,30 \mathrm{a}$ & $0,27 \mathrm{a}$ & $0,06 \mathrm{a}$ \\
\hline 120 & & & $25,17 \mathrm{a}$ & $0,27 \mathrm{a}$ & $0,07 \mathrm{a}$ \\
\hline 180 & & & $26,69 \mathrm{a}$ & $0,29 \mathrm{a}$ & $0,08 \mathrm{a}$ \\
\hline 0 & \multirow{4}{*}{$60-123$} & \multirow{4}{*}{49,8} & $31,15 \mathrm{a}$ & - & - \\
\hline 60 & & & $10,17 \mathrm{~b}$ & - & - \\
\hline 120 & & & $5,36 \mathrm{c}$ & - & - \\
\hline 180 & & & $7,35 \mathrm{c}$ & - & - \\
\hline 0 & \multirow{4}{*}{ Total } & \multirow{4}{*}{96,8} & $71,06 \mathrm{a}$ & $0,04 \mathrm{~b}$ & - \\
\hline 60 & & & $42,47 \mathrm{ab}$ & $0,27 \mathrm{a}$ & $0,06 \mathrm{a}$ \\
\hline 120 & & & $30,53 \mathrm{~b}$ & $0,27 \mathrm{a}$ & $0,07 \mathrm{a}$ \\
\hline 180 & & & $34,04 \mathrm{~b}$ & $0,29 \mathrm{a}$ & $0,08 \mathrm{a}$ \\
\hline
\end{tabular}

*DAE: dias após emergência. Médias seguidas por letras comuns não diferem entre si a $5 \%$ pelo teste de Tukey. 
Para o segundo cultivo de milho, safra 2007 (Quadro 5), as drenagens internas a $0,80 \mathrm{~m}$ de profundidade, diferentemente do primeiro cultivo (Quadro 3), apresentaram diferenças estatísticas entre tratamentos no primeiro (0-60 DAE) e segundo (60118 DAE) períodos estudados. As drenagens internas, nos dois períodos, apresentaram-se maiores para o tratamento em que não se aplicou $\mathrm{N}$, diferindo significativamente dos tratamentos em que se aplicaram 120 e $180 \mathrm{~kg} \mathrm{ha}^{-1}$ de N, devido, possivelmente, a uma maior quantidade de matéria seca (milho safrinha 2006 e braquiária) nesses tratamentos, a qual ajudou na retenção da água no solo.

Os menores valores de drenagem, no segundo cultivo de milho (Quadro 5), foram obtidos no período de 60-118 DAE (época do florescimento), devido à menor precipitação pluvial, enquanto para o primeiro cultivo de milho a escassez de chuva ocorreu nos dois períodos estudados. Na contabilização final do ciclo da cultura (safra 2007), observa-se que as drenagens internas a $0,80 \mathrm{~m}(355,282,237$ e $252 \mathrm{~mm})$, para os tratamentos com $0,60,120$ e $180 \mathrm{~kg} \mathrm{ha}^{-1}$ de N, respectivamente, foram maiores que as do primeiro cultivo de milho, devido a maior precipitação pluvial.

Quanto à lixiviação de $\mathrm{NO}_{3}{ }^{-}$, nos dois períodos da cultura (Quadro 5), os resultados apresentaram-se maiores nos tratamentos com 120 e $180 \mathrm{~kg} \mathrm{ha}^{-1} \mathrm{de} \mathrm{N}$, diferindo daqueles com 0 e $60 \mathrm{~kg} \mathrm{ha}^{-1}$ de $\mathrm{N}$. O total de $\mathrm{NO}_{3}{ }^{-}$lixiviado $\left(0,28,5,88,23,16\right.$ e $\left.23,26 \mathrm{~kg} \mathrm{ha}^{-1}\right)$ ou o total de $\mathrm{N}-\mathrm{NO}_{3}{ }^{-}$lixiviado $(0,06,1,32,5,23 \mathrm{e}$

Quadro 4. Precipitação pluvial, drenagem interna e lixiviação de nitrato, total (fertilizante e outras fontes) e proveniente do fertilizante (PF), a $0,80 \mathrm{~m}$ de profundidade, na cultura da braquiária e durante o período de pousio

\begin{tabular}{|c|c|c|c|c|c|}
\hline \multirow{2}{*}{ Dose de N } & \multirow{2}{*}{$\mathbf{D A E} \mathbf{E}^{(1)}$} & \multirow{2}{*}{ Precipitação } & \multirow{2}{*}{ Drenagem interna } & \multicolumn{2}{|c|}{ Lixiviação de $\mathrm{NO}_{3}^{-}$} \\
\hline & & & & Total & PF \\
\hline $\mathrm{kg} \mathrm{ha}^{-1}$ & \multirow{5}{*}{$0-80$} & \multirow{5}{*}{439,9} & - & \multicolumn{2}{|c|}{$-\mathrm{kg} \mathrm{ha}^{-1}$} \\
\hline 0 & & & $307,54 \mathrm{a}^{(2)}$ & $0,50 \mathrm{~b}$ & - \\
\hline 60 & & & $240,61 \mathrm{~b}$ & $0,56 \mathrm{~b}$ & $0,18 \mathrm{c}$ \\
\hline 120 & & & $161,45 \mathrm{c}$ & $26,41 \mathrm{a}$ & $1,85 \mathrm{~b}$ \\
\hline 180 & & & $175,81 \mathrm{c}$ & 39,81 a & $2,90 \mathrm{a}$ \\
\hline 0 & \multirow{4}{*}{ Pousio } & \multirow{4}{*}{255,4} & $96,31 \mathrm{a}$ & $0,04 \mathrm{a}$ & - \\
\hline 60 & & & $52,82 \mathrm{~b}$ & $0,03 \mathrm{a}$ & $0,01 \mathrm{a}$ \\
\hline 120 & & & $20,10 \mathrm{c}$ & $0,02 \mathrm{a}$ & $0,03 \mathrm{a}$ \\
\hline 180 & & & $27,82 \mathrm{c}$ & $0,02 \mathrm{a}$ & $0,03 \mathrm{a}$ \\
\hline 0 & \multirow{4}{*}{ Total } & \multirow{4}{*}{695,30} & $403,85 \mathrm{a}$ & $0,54 \mathrm{~b}$ & - \\
\hline 60 & & & $293,43 \mathrm{~b}$ & $0,60 \mathrm{~b}$ & $0,19 \mathrm{c}$ \\
\hline 120 & & & $181,55 \mathrm{c}$ & $26,43 \mathrm{a}$ & $1,89 \mathrm{~b}$ \\
\hline 180 & & & $203,63 \mathrm{c}$ & $39,83 \mathrm{a}$ & $2,93 \mathrm{a}$ \\
\hline
\end{tabular}

*DAE: dias após emergência. Médias seguidas pelas mesmas letras não diferem entre si a $5 \%$ pelo teste de Tukey.

Quadro 5. Precipitação pluvial, drenagem interna e lixiviação de nitrato, total (fertilizante e outras fontes) e proveniente do fertilizante (PF), a 0,80 m de profundidade, na cultura do milho 2007 (segundo cultivo)

\begin{tabular}{|c|c|c|c|c|c|}
\hline \multirow{2}{*}{ Dose de $\mathbf{N}$} & \multirow{2}{*}{$\mathbf{D A E} \mathbf{E}^{(1)}$} & \multirow{2}{*}{ Precipitação } & \multirow{2}{*}{ Drenagem interna } & \multicolumn{2}{|c|}{ Lixiviação de $\mathrm{NO}_{3}^{-}$} \\
\hline & & & & Total & PF \\
\hline $\mathrm{kg} \mathrm{ha} \mathrm{a}^{-1}$ & \multirow{5}{*}{$0-60$} & \multirow{5}{*}{351,1} & $\mathrm{~m} \longrightarrow$ & 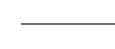 & - \\
\hline 0 & & & $337,28 \mathrm{a}^{*}$ & $0,24 \mathrm{c}$ & - \\
\hline 60 & & & $272,49 a b$ & $5,72 \mathrm{~b}$ & - \\
\hline 120 & & & $231,46 \mathrm{~b}$ & $22,20 \mathrm{a}$ & $0,15 \mathrm{a}$ \\
\hline 180 & & & $245,54 \mathrm{~b}$ & $22,24 \mathrm{a}$ & $0,19 \mathrm{a}$ \\
\hline 0 & \multirow{4}{*}{$60-118$} & \multirow{4}{*}{67,8} & $17,75 \mathrm{a}$ & $0,04 \mathrm{c}$ & - \\
\hline 60 & & & $9,06 \mathrm{~b}$ & $0,16 \mathrm{~b}$ & - \\
\hline 120 & & & $5,61 \mathrm{~b}$ & $0,96 \mathrm{a}$ & - \\
\hline 180 & & & $6,43 \mathrm{~b}$ & $1,02 \mathrm{a}$ & - \\
\hline 0 & \multirow{4}{*}{ Total } & \multirow{4}{*}{418,9} & $355,03 \mathrm{a}$ & $0,28 \mathrm{c}$ & - \\
\hline 60 & & & $281,55 \mathrm{ab}$ & $5,88 \mathrm{~b}$ & - \\
\hline 120 & & & 237,06 b & 23,16 a & $0,15 \mathrm{a}$ \\
\hline 180 & & & $251,96 \mathrm{~b}$ & $23,26 \mathrm{a}$ & $0,19 \mathrm{a}$ \\
\hline
\end{tabular}

*DAE: dias após emergência. Médias seguidas pelas mesmas letras não diferem entre si a $5 \%$ pelo teste de Tukey. 
$5,25 \mathrm{~kg} \mathrm{ha}^{-1}$ ) diferiram entre os tratamentos e apresentaram-se superiores aos do primeiro cultivo. Esses resultados indicam que o aumento de dose de $\mathrm{N}$ em cobertura proporciona maiores perdas de $\mathrm{N}$ proveniente do fertilizante, concordando com Sainz Rozas et al. (2004), que obtiveram aumento na lixiviação de $\mathrm{NO}_{3}^{-}$quando se aumentou a dose de $\mathrm{N}$ na aplicação no estádio $\mathrm{V}_{6}$ da cultura do milho. Costa et al. (2003) registraram perdas de $\mathrm{N}$ por lixiviação de $66,5 \mathrm{~kg} \mathrm{ha}^{-1}$ quando aplicaram $200 \mathrm{~kg} \mathrm{ha}^{-1}$ de $\mathrm{N}$ no plantio de milho. Embora com acúmulo de resíduos vegetais na superfície do solo, fornecido pelo sistema plantio direto, a chuva ocorrida no período favoreceu a lixiviação do nutriente. Halvorson et al. (2001), utilizando trigo, e Sainju \& Singh (2001), com milho, concluíram que abaixo de $1,50 \mathrm{~m}$ de profundidade 0 sistema convencional acumulou mais $\mathrm{NO}_{3}{ }^{-}$do que o plantio direto. Weed \& Kanwar (1996) reportaram que a perda de $\mathrm{NO}_{3}^{-}$em sistema plantio direto foi $74 \mathrm{~kg} \mathrm{ha}^{-1}$ menor do que em plantio convencional. Para o efeito residual do fertilizante no milho (Quadro 5), a $0,80 \mathrm{~m}$ de profundidade, os resultados de $\mathrm{NO}_{3}^{-}$ proveniente do fertilizante mostraram-se praticamente desprezíveis, assim como no primeiro cultivo, e foram iguais estatisticamente para os tratamentos em que foram aplicados 120 e $180 \mathrm{~kg} \mathrm{ha}^{-1}$ de $\mathrm{N}(0,15$ e $\left.0,19 \mathrm{~kg} \mathrm{ha}^{-1}\right)$.

\section{CONCLUSÕES}

1. A drenagem interna diminuiu com o aumento das doses de $\mathrm{N}$ aplicadas para a sucessão de culturas estudada, variando de 31,5 a $73,4 \%$ da precipitação pluvial total $(97 \mathrm{~mm})$ durante o primeiro cultivo de milho, de 26,1 a 58,1 \% da precipitação pluvial total (695 mm) no cultivo da braquiária e pousio e de 56,6 a $87,4 \%$ do total de $419 \mathrm{~mm}$ de precipitação pluvial no segundo cultivo de milho.

2. A lixiviação de $\mathrm{NO}_{3}{ }^{-}$total (do fertilizante e outras fontes) foi muito baixa no primeiro cultivo de milho para todas as doses de $\mathrm{N}$ aplicadas e significativa para as doses de 120 e $180 \mathrm{~kg} \mathrm{ha}^{-1}$ nos períodos da cultura de braquiária mais pousio $\left(26,16 \mathrm{~kg} \mathrm{ha}^{-1}\right.$ para a dose de $120 \mathrm{~kg} \mathrm{ha}^{-1}$ e $39,8 \mathrm{~kg} \mathrm{ha}^{-1}$ para a de $180 \mathrm{~kg} \mathrm{ha}^{-1}$ ) e da segunda cultura de milho (aproximadamente $23 \mathrm{~kg} \mathrm{ha}^{-1}$ para ambas as doses).

3. A lixiviação de $\mathrm{NO}_{3}{ }^{-}$proveniente do fertilizante foi praticamente nula no primeiro cultivo de milho e, em geral, baixa durante o cultivo de braquiária e o segundo cultivo de milho.

\section{LITERATURA CITADA}

AMADO, T.J.C.; MIELNICZUK, J. \& AITA, C. Recomendação de adubação nitrogenada para o milho no Rio Grande do Sul e Santa Catarina adaptada ao uso de culturas de cobertura do solo, sob sistema plantio direto. R. Bras. Ci. Solo, 26:241-248, 2002.
BÜLL, L.T. Nutrição mineral do milho. In: BÜLL, L.T. \& CANTARELLA, H., eds. Cultura do milho: Fatores que afetam a produtividade. Piracicaba, Potafos, 1993. p.63146.

CARVALHO, M.A.C.; LAZARINI, E.; ARF, O. \& SÁ, M.E. Efeito da rotação de culturas e adubação verde sobre o rendimento do feijoeiro "de inverno" (Phaseolus vulgaris L.). In: REUNIÃO NACIONAL DE PESQUISA DE FEIJÃO, 6., Salvador, 1999. Anais. Goiânia, Embrapa/ EBDA, 1999. p.649-651.

CASTRO, L.G.; LIBARDI, P.L. \& Jong van LIER, Q. Soil water dynamics in a Brazilian infiltration terrace under different management practices. In: PAGLIAI, M. \& JONES, R., orgs. Sustainable land management. Environmental protection: A soil physical approach. Reiskirchen, ISSDS, 2002. v.35. p.191-198. (Advances in GeoEcology, 35)

COSTA, J.L.; BEDMAR, F.; DANIEL, P.E. \& APARÍCIO, V.C. Nitrate and atrazine leaching from corn in the Argentinean Humid Pampas. In: INTERNATIONAL WORKSHOP ON GROUNDWATER RISK ASSESSMENT AT CONTAMINATED SITES AND INTEGRATED SOIL AND WATER PROTECTION, 2., Tubingen, 2003. Proceedings. Tubingen, Eberhard Karls Universität Tubingen, 2003. p.241-245.

EMPRESA BRASILEIRA DE PESQUISA AGROPECUÁRIA EMBRAPA. Centro Nacional de Pesquisa de Solos. Sistema brasileiro de classificação de solos. 2.ed. Rio de Janeiro, 2006. 306p.

FANCELLI A.L. \& DOURADO NETO, D. Produção de milho em terras baixas. In: FANCELLI, A.L. \& DOURADO NETO, D., eds. Milho: Tecnologia e produção. Piracicaba, ESALQ/USP/LVP, 2005. p.21-33.

FERNANDES, F.C.S.; LIBARDI, P.L. \& CARVALHO, L.A. Internal drainage and nitrate leaching in corn-black oatcorn succession with two split nitrogen applications. Sci. Agric., 63:483-492, 2006.

FRANÇA, G.E.; BAHIA FILHO, A.F.C.; VASCONCELLOS, C.A. \& SANTOS, H.L.A. Adubação nitrogenada no Brasil. Ilhéus, CEPLAC, SBCS, 1985. p.107-124.

GAVA, G.J.C. Compartimentalização do nitrogênio no sistema solo-planta na implantação do semeadura direta no ciclo da cultura do milho. Piracicaba, Escola Superior de Agricultura Luiz de Queiroz, 2003. 125p. (Tese de Doutorado)

GEE, S.W. \& BAUDER, J.C. Particle size analysis. In: KLUTE, A., ed. Methods of soil analysis: Physical and mineralogical methods. Madison, American Society of Agronomy, 1986. p.383-412.

GINE, M.F.; BERGAMIN FILHO, H.; ZAGATO, E.A.G. \& REIS, B.F. Simultaneous determination of nitrate and nitrite by flow injection analysis. Anal. Chim. Acta, 114:191-197, 1980.

GOLLANY, H.; MOLINA, J.A.; CLAPP, C.; ALLMARAS, R.; LAYESE, M.; BAKER, J. \& CHENG, H. Nitrogen leaching and denitrification in continuous corn as related to residue management and nitrogen fertilization. Disponível em: $<$ http://www.ars.usda.gov/research/publications/ publications.htm>. Acesso em: 15 jan. de 2005. 
HALVORSON, A.D.; WIENHOLD, B.T. \& BLACK, A.L. Tillage and nitrogen fertilization influence grain and soil nitrogen in a annual cropping system. Agron. J., 93:836-841, 2001.

HILLEL, D.A.; KRENTOS, V.K. \& STILIANOV, Y. Procedure an test an internal drainage method for measuring soil hydraulic characteristics in situ. Soil Sci., 114:395-400, 1972.

HOEFT, R.G. Desafios para a obtenção de altas produtividades de milho e de soja nos EUA. Piracicaba, Potafos, 2003. p.1-4. (Informações Agronômicas, 104)

IVANKO, S. Recent progress in the use of ${ }^{15} \mathrm{~N}$ in research on nitrogen balance studies sin soil plant relationship. In: SYMPOSIUM ON THE USE OF ISOTOPE AND RADIATION IN SOIL-PLANT RELATIONSHIPS INCLUING FORESTRY, Vienna, 1972. Proceedings. Vienna, IAEA, 1972. p.483-497.

KIEHL, E.J. Manual de edafologia. São Paulo, Agronômica Ceres, 1979. 262p.

KIEHL, J.C. Nitrogênio: Dinâmica e disponibilidade no solo. In: KIEHL, J.C. Curso de atualização em fertilidade do solo. Campinas, Fundação Cargill, 1987. p.139-157.

LIBARDI, P.L. \& REICHARDT, K. Destino da uréia aplicada a um solo tropical. R. Bras. Ci. Solo, 2:40-44, 1978.

LIBARDI, P.L. Dinâmica da água no solo. 3.ed. Piracicaba, P.L.Libardi, 2005. 509p.

LIMA, V.E. \& LIMA, J.M.J.C. Fundamentos da pedologia. Curitiba, Universidade Federal do Paraná, 2000.

MAGALHÃES, P.C.; DURÃES, F.O.M. \& PAIVA, E. Fisiologia da planta de milho. Sete Lagoas, Embrapa/CNPMS, 1995. 27p. (Circular Técnica, 20)

MOREIRA, F.M.S. \& SIQUEIRA, J.O. Microbiologia e bioquímica do solo. Lavras, Universidade Federal de Lavras, 2002. 625p.

RAIJ, B.van; CANTARELLA, H.; QUAGGIO, J.A. \& FURLANI, A.M. Recomendações de adubação e calagem para o Estado de São Paulo. Campinas, Instituto Agronômico de Campinas, 1997. 285p. (Boletim Técnico, 100)
RAIJ, B.van; ANDRADE, J.C.; CANTARELLA, H. \& QUAGGIO, J.A., eds. Análises químicas para avaliação de fertilidade de solos tropicais. Campinas, Instituto Agronômico de Campinas, 2001. 284p.

SÁ, J.C. Manejo do nitrogênio na cultura do milho no sistema plantio direto. Passo Fundo, Aldeia Norte, 1996. 24p.

SAINJU, U.M. \& SINGHI, B.P. Tillage, cover crop and killplanting date effects on corn yield and soil nitrogen. Agron. J., 93:878-886, 2001.

SAINZ ROZAS, H.R.; ECHEVERRIA, H.E. \& BARBIERI, P.A. Nitrogen balance as affected by application time and nitrogen fertilizer rate in irrigated no-tillage maize. Am. Soc. Agron., 96:1622-1631, 2004.

SENTELHAS, P.C.; PEREIRA, A.R.; MARIN, F.R.; ANGELOCCI, L.R.; ALFONSI, R.R.; CARAMORI, P.H. \& SWART, S. BHBRASIL - Balanços hídricos climatológicos de 500 localidades brasileiras. Disponível em: <http:// www.lce.esalq.usp.br/bhbrasil/Saopaulo>. Acesso em: 19 abr. de 2009.

SEXTON, B.T.; MONCRIEF, J.F.; ROSEN, C.J.; GUPTA, S.C. \& CHENG, H.H. Optimizing nitrogen and irrigation inputs for corn based on nitrate leaching and yield on a course-textured soil. J. Environ. Quality, 25:983-992, 1996.

SOGBEDJI, J.M.; van ES, H.M. \& YANG, C.L. Nitrate leaching and nitrogen budget as affected by maize nitrogen rate and soil type. J. Environ. Quality, 29:1813-1820, 2000.

SOIL SURVEY STAFF. Keys to soil taxonomy. 9.ed. Washington, DC, United States Department of Agriculture (USDA) - Natural Resources Conservation Service, 2003. 332p.

TRIVELIN, P.C.O.; SAlATI, E. \& MATSUI, E. Preparo de amostras para análise de ${ }^{15} \mathrm{~N}$ por espectrometria de massas. Piracicaba, CENA/USP, 1973. 41p. (Boletim Técnico, 2)

WEED, D.A.J. \& KANWAR, R.S. Nitrate and water present and flowing from root-zone soil. J. Environ. Quality, 25:709-719, 1996. 